\title{
Hamlet e o Problema da Verdade ${ }^{1}$
}

\author{
Maria Thereza Ávila Dantas Coelho ${ }^{2}$ \\ Universidade do Salvador \\ Colégio de Psicanálise da Bahia
}

\begin{abstract}
RESUMO - Este artigo discute o problema da verdade, a partir da obra Hamlet e da produção teórica da Psicanálise. Objetiva mostrar a centralidade de tal problema, tanto no teatro quanto no processo analítico, e explorar alguns de seus aspectos tais como a estrutura de ficção e as relações com o desejo e as pulsões. Após ressaltar a dimensão mortífera da verdade, problematiza as suas ligações com o saber e a posição do analista. Para tanto, utiliza-se da clássica interpretação de Freud sobre a peça shakespeariana e de avanços teóricos e interpretativos efetuados por Jacques Lacan. Por fim, o presente estudo reafirma a posição segundo a qual o que se espera de um analista é que ele faça funcionar seu saber em termos de verdade, e não o contrário. Nessa direção, sublinha que é impossível uma apreensão totalizadora da verdade, apontando que sempre algo resta por conceber.
\end{abstract}

Palavras-chave: verdade; Hamlet; psicanálise; teatro; desejo.

\section{Hamlet and the Problem of the Truth}

\begin{abstract}
This paper is aimed at discussing the problem of the truth, based on the play Hamlet and on the theoretical production of the Psychoanalysis. It is intended to show the centrality of the matter, in the theater as well as in the analytical process and also to explore some of its aspects such as the fiction structure and the relations with desire and instincts. After emphasizing the lethal dimension of the truth, it argues its connections with knowledge and the analyst's position. To attain this aim, the classical interpretation of Freud about the Shakespeare's play and the theoretical and interpretative advances made by Jacques Lacan were used. Finally, this study corroborates the position that the analyst must express his knowledge in terms of the truth, and not the opposite. In this direction, it highlights that it is impossible to achieve a total apprehension of the truth, pointing out that there is always something to be conceived.
\end{abstract}

Key words: truth; Hamlet; psychoanalysis; theater; desire.

Por que mentes para mim, sim, por que mentes para mim, dizendo-me que vais a Cracóvia, para que eu creia que estás indo a Lemberg, quando, na realidade, é a Cracóvia que vais? (Lacan, 1957/1998, p. 22)

Muitos são os aspectos pelos quais o teatro de Shakespeare tem despertado interesse no campo da psicanálise. Não são poucas, por exemplo, as referências desse dramaturgo nas obras de Freud e Lacan. No que diz respeito à peça Hamlet, só na obra de Freud ela foi citada em 23 de seus textos, incluindo a primeira citação em carta a Fliess de 15 de outubro de 1897. Alguns estudos específicos sobre essa peça também têm sido feitos por outros autores, dentre eles Williamson (1950), Quijano (1962), Pimstein (1972), Vygotsky (1999), Iasi (2002), Lins (2002), Pereira (2002), Bloom (2004) e Cantor (2004). Em meio a esses diversos trabalhos, o aspecto que destaco aqui, para tecer algumas considerações, é a questão da verdade. Creio que podemos afirmar que a verdade se encontra mesmo no coração dessa obra. Mas em que isso nos captura? Talvez

1 Trabalho apresentado na III Ciranda de Psicanálise e Arte da Escola Lacaniana do Rio de Janeiro, no ano de 2005.

2 Endereço: Rua Theodomiro Baptista, 150, apto.102, Rio Vermelho, Salvador, BA, Brasil 41940-320.E-mail: therezacoelho@pop.com.br o significante "verdade", nos tempos atuais, tenha invadido as nossas casas, com os escândalos de corrupção na esfera política, que a televisão brasileira e todos os meios de comunicação em massa não cansam de propagar e de tornar nossa companheira em todas as horas do dia e à mesa de jantar. Talvez estejamos impregnados com a mentira pública, atordoados com a face falsa da moralidade corrupta, que tão verdadeiramente tem se manifestado. Entretanto, de um outro lugar, não mais público e sim privado, esse significante parece nos convocar. Por acaso a verdade não se encontra, também ela, no coração de uma análise? Em que a verdade tem a ver conosco?

Em 1960, em seu texto "Subversão do Sujeito e Dialética do Desejo", Lacan assinalou que, para que a fala possa portar a verdade, é preciso que ela também possa mentir (Lacan, 1960/1998). Ele sublinhou que um animal pode até fingir, despistar, esboçando, para sua presa, uma falsa retirada. Entretanto, ele não pode fingir fingir, como os humanos. Não pode fazer com que um outro tome como falsos rastros que são verdadeiros. Um pouco mais tarde, em 1966, no seu texto "A Ciência e a Verdade", Lacan lançou para os psicanalistas algumas questões que considero cruciais: "A verdade como causa, irão vocês, psicanalistas, recusar-se a assumir sua questão, quando foi a partir disso que se alçou sua carreira? Se existem praticantes para quem a verdade como tal supostamente age, não são vocês?" (Lacan, 1966/1998, p. 883). Freud só inventou o campo psicanalítico porque foi movido pela paixão de desvelar a verdade (Lacan, 1950/1998). Em 
sua sede de verdade, ele afirmou que, em algum lugar, o inconsciente se mostra (Lacan, 1964/1985). Ele soube deixar que a verdade falasse através do inconsciente (Lacan, 1966/1998).

\section{A Verdade entre Dois}

Contrariamente a Jones (1949), que viu em Hamlet apenas a questão do Complexo de Édipo, para Lacan (1958), esta peça trata, justamente, da relação do sujeito com a verdade. Em Hamlet, a questão da verdade se apresenta em vários momentos, dentre eles, durante o diálogo entre Polônio e seu filho Laertes, entre Hamlet e o fantasma de seu pai morto, entre Polônio e seu criado Reinaldo e no espetáculo de teatro encenado para o Rei Cláudio. É sempre entre dois que a verdade é aí colocada, ainda que ela possa estar em outro lugar que não aquele situado pela fala. Nesse sentido, a verdade é algo que diz respeito necessariamente ao domínio do subjetivo, do ficcional, e é nisto que ela se separa da dimensão factual (Lacan, 1957/1998, 1958/1998).

Verificamos, entretanto, que, nos diversos momentos em que o problema da verdade é apresentado nessa peça, ele adquire conotações diferentes. No diálogo entre Polônio e Laertes, por exemplo, a verdade é colocada como um imperativo moral. A vertente imaginária desse problema é a que embasa, justamente, a regra moral da sociedade, que dá à verdade uma primazia cultural (Lacan, 1936/1998). Vejamos o que Polônio diz a seu filho: "Sobretudo, sê sempre verdadeiro para contigo mesmo e disto seguir-se-á, como o dia segue a noite, não poderes tu ser falso para com ninguém" (Shakespeare, 1601/2003, p. 70).

Também na conversa entre Hamlet e o espectro de seu pai, a valorização cultural da verdade nos é apresentada quando o espectro ressalta a sua fidelidade conjugal à exesposa. Ele revela:

Oh! Hamlet, que queda foi a dela! Cair do meu amor, que tinha tal dignidade que se havia conservado inalteravelmente fiel ao juramento dado na cerimônia do casamento, nos braços dum miserável, cujos dons naturais eram tão mesquinhos, comparados com os meus! (Shakespeare, 1601/2003, pp. 92-93).

Essas palavras do espectro apontam, por outro lado, para uma outra dimensão da verdade, a verdade do desejo da mãe, no que ele tem de enigmático, incompreensível e/ou absurdo. Elas apontam para a dimensão genital desse desejo, na medida em que essa mãe rapidamente faz o luto da morte de seu marido (Lacan, 1958). Sabemos que, dois meses após o falecimento do Rei Hamlet, a Rainha Gertrudes se casa com o cunhado Cláudio.

\section{A Destrutividade}

Um outro aspecto importante, revelado no diálogo entre Hamlet e o espectro de seu pai, é a relação entre a verdade e a destrutividade. No que diz respeito a esse elemento pulsional, verificamos que, em nome da verdade, o ódio do pai e o de Hamlet são apresentados como apoiados no amor à Rainha. $\mathrm{O}$ espectro ordenou a Hamlet que vingasse a sua morte tirando a vida de seu tio, sem, entretanto, nada fazer contra sua mãe.
Ele transmitiu a Hamlet um imperativo cruel, superegóico, de morte. Eu o cito:

Quando eu, segundo o meu costume, dormitava no jardim, teu tio aproximou-se de mim pé ante pé, àquela hora da tarde, em que estava sem defesa, e, com um frasco cheio do maldito suco do meimendro, lançou nos meus ouvidos esse leproso líquido, que é tão inimigo do sangue do homem que, vivo como o azougue, corre através das portas naturais e sinuosidades mais secretas do corpo e com um vigor repentino, semelhante às gotas de ácido no leite, coagula e coalha o sangue fluido e sadio; assim fez ele ao meu sangue; de repente uma erupção como herpes cobriu de vil e repugnante crosta o meu corpo liso, tornando-o como o dum leproso. Foi assim que eu, durante o meu sono, fui privado ao mesmo tempo da minha vida, da minha coroa, da minha rainha, pelas mãos dum irmão meu, arrancado do mundo com a alma toda abismada no pecado, sem estar preparado para a morte, sem sacramentos, sem a extrema-unção, e, expulso, fui prestar as minhas contas, com todas as faltas sobre a cabeça, sem ter tido tempo de fazer o meu exame de consciência. Oh! É horrível! Horrível! Horrivel! Se tu tens coração não consintas em semelhante coisa; não permitas que o leito real da Dinamarca se transforme em coito da luxúria e do incesto danado. Mas qualquer que seja o plano que sigas nesta vingança, que o teu espírito se não macule, que a tua alma não ponha em prática, seja o que for, contra tua mãe; abandona-a ao castigo do Céu, deixa que esses espinhos que ela agasalha no seio se encarreguem de a picar e despedaçar (Shakespeare, 1601/2003, pp. 93-96).

Tais palavras produziram efeitos de destruição. Mais uma vez, do lado do absurdo, do inefável e do ficcional, a verdade foi apresentada pela boca de um espectro que, além disso, encontrava-se dormindo quando foi assassinado! Ainda que Hamlet tivesse tido dificuldade de realizar o voto paterno, o fato é que, algum tempo após ter escutado as palavras de seu pai, todos os personagens principais da peça faleceram: Polônio (o camareiro-mor), Ofélia (filha de Polônio e amada de Hamlet), Laertes (filho de Polônio), Cláudio (o novo Rei, tio de Hamlet), Gertrudes (a Rainha, sua mãe) e o próprio Hamlet. Hamlet sucumbiu, portanto, ao mesmo destino de seu pai, quando foi envenenado, pelo ouvido, com a fala dele (Lacan, 1958). A verdade revelada por seu pai foi assassina, o que nos mostra que a verdade também pode matar. Ela pode portar, portanto, essa dimensão agressiva, até mesmo mortífera, a depender do uso que se faça dela. Vemos, aí, o quanto a vingança é filha do ódio: é a pulsão de morte, apoiada em pretextos criados pela civilização. A curiosidade humana pode, então, chegar às raias da perversão e se colocar a serviço do masoquismo, quando alguém busca sofrer através de uma verdade que lhe foi revelada sob uma demanda de saber. Isso não é radicalmente diferente da situação na qual um voyeurista obriga ou força o outro a se desnudar, nem da situação na qual a curiosidade pode também se apresentar como sádica, produzindo no outro uma intensa angústia por ter de fazer uma revelação.

O diálogo entre Hamlet e o espectro de seu pai nos revela, ainda, a relação entre a verdade e a proibição. Nele, o Rei Hamlet nos diz que nem toda a verdade pode ser dita. Mesmo dentro do conjunto do dizível, há verdades que estão 
proibidas. Encontramos isso nas palavras do espectro, quando este pronuncia:

Se me não fosse proibido revelar os segredos da minha prisão, far-te-ia tal narrativa que a menor palavra despedaçaria a tua alma, gelaria o teu sangue, faria saltar os teus olhos das suas órbitas como duas estrelas para fora das suas esferas, destruiria a harmonia da tua cabeleira simetricamente anelada e faria erguer em pé cada um dos teus cabelos, como dardos de porcoespinho furioso; mas estas revelações não são para ouvidos mortais (Shakespeare, 1601/2003, pp. 89-90).

Verificamos, assim, que diferentes cenas da peça focalizam distintos aspectos do problema da verdade. Isso nos remete à posição de Motta (2006), segundo a qual a verdade que importa ao teatro é a verdade da cena, em sua parcialidade ou em seu caráter complementar. Para essa autora, no teatro o desvelamento e a revelação gradativa da verdade aproximamse dos procedimentos adotados no tratamento psicanalítico. Da mesma forma e inversamente, a própria rememoração produzida pelo sujeito em análise tem o caráter de uma construção equivalente à construção da cena teatral.

\section{O Teatro}

Passemos agora à cena hamletiana na qual um espetáculo de teatro é encenado para o Rei Cláudio. Diante das palavras do espectro, Hamlet hesitou: teriam sido elas verdadeiras ou proferidas pelo Diabo disfarçado enquanto fantasma do pai? Freud (1900/1980) sublinhou que tal vacilação foi interpretada de forma diferente por distintos autores. A partir dela, ele construiu a sua interpretação edipiana, afirmando estar essa hesitação ligada à identificação de Hamlet com o tio paterno. Eu cito Freud:

Outra das grandes criações da poesia trágica, o Hamlet de Shakespeare, tem suas raízes no mesmo solo que Oedipus Rex. (...) No Oedipus, a fantasia infantil imaginária que subjaz ao texto é abertamente exposta e realizada, como o seria num sonho. Em Hamlet ela permanece recalcada; $e$-tal como no caso de uma neurose - só ficamos cientes de sua existência através de suas conseqüências inibidoras. (...) A peça se alicerça nas hesitações de Hamlet em cumprir a tarefa de vingança que lhe é atribuída; mas seu texto não oferece nenhuma razão ou motivo para essas hesitações, e uma imensa variedade de tentativas de interpretá-las falhou na obtenção de qualquer resultado. (...) $O$ enredo do drama nos mostra, contudo, que Hamlet está longe de ser representado como uma pessoa incapaz de adotar qualquer atitude. Vemo-lo fazer isso em duas ocasiões: primeiro, num súbito rompante de cólera, quando trespassa com a espada o curioso que escuta a conversa por trás da tapeçaria, e em segundo lugar, de maneira premeditada e até ardilosa, quando, com toda a insensibilidade de um príncipe da Renascença, envia os dois cortesãos à morte, que fora planejada para ele mesmo. o que é, então, que o impede de cumprir a tarefa imposta pelo fantasma do pai? A resposta, mais uma vez, está na natureza peculiar da tarefa. Hamlet é capaz de fazer qualquer coisa - salvo vingar-se do homem que eliminou seu pai e tomou o lugar deste junto a sua mãe, o homem que lhe mostra os desejos recalcados de sua própria infância realizados. Desse modo, o ódio que deveria impeli-lo à vingança é nele substituído por auto-recriminações, por escrúpulos de consciência que ofazem lembrar que ele próprio, literalmente, não é melhor do que o pecador a quem deve punir. Aqui traduzi em termos conscientes o que se destinava a permanecer inconsciente na mente de Hamlet (Freud, 1900/1980, pp. 280-281).

"Sua consciência [moral] é seu sentimento inconsciente de culpa" (Freud, 1969/1980, p. 359). Tal interpretação freudiana não foi aceita por todos os estudiosos dessa peça shakespeariana (Bloom, 2000). Ainda na trilha da hesitação de Hamlet, um aspecto digno de nota para explorar os efeitos de uma representação teatral no espectador é o caminho utilizado por Hamlet para chegar à verdade sobre a morte de seu pai. Hamlet confirmou as palavras do espectro através do teatro. Ele pensou:

Sempre tenho ouvido dizer que há criminosos que, quando assistem a uma representação dramática, são de tal modo atingidos na alma pela ilusão da cena que proclamam alto $e$ bom som os seus malefícios; porque o homicídio, ainda que não tenha língua, encontra para falar órgãos miraculosos (Shakespeare, 1601/2003, pp. 191-192).

Hamlet solicitou, então, a um grupo de atores que encenasse uma estória escrita por ele, para toda a corte. Essa estória dizia respeito, justamente, ao que lhe contara o espectro de seu pai. Vemos que, mais uma vez, a verdade é apresentada, aí, por uma estrutura de ficção (Lacan, 1958). Hamlet definiu que, a depender da reação de seu tio a essa encenação, a estória seria considerada por ele como verdadeira ou falsa. $\mathrm{O}$ que sucedeu, então, foi que, durante a apresentação de teatro, o Rei ficou muito perturbado com o espetáculo e se retirou do local, interrompendo-o. A partir daí, ele passou a exprimir um sentimento de culpa pelo assassinato de seu irmão.

Que poder é este, o do teatro, que consegue abalar um criminoso que, antes, parecia ter cometido friamente um assassinato sem se sentir, por ele, culpado? O que fez com que o Rei, que não demonstrava nenhum remorso por ter matado seu irmão e por ter se casado com a sua cunhada, depois dessa encenação parecesse perseguido pelo sentimento de culpa que se propagou em sua alma? A problematização dos efeitos de uma encenação teatral no espectador é algo que já foi efetuado por Freud num texto que escreveu nos anos de 1905-1906, e que só foi publicado após a sua morte, em 1942: "Tipos Psicopáticos no Palco". Nesse texto, Freud (1942/1980) parte do conceito de recalque para pensar como o espectador pode sentir prazer com personagens psicopatas no teatro. Vejam que, aí, a psicopatia está representada apenas no palco. Freud (1942/1980) não discorre sobre os efeitos de tal encenação entre espectadores psicopatas, por exemplo, pois pensa essa questão a partir do campo da neurose. Nesse contexto, ele afirma que a pré-condição para tal fruição de prazer é que o espectador deve ser, ele próprio, um neurótico. Somente tais pessoas podem sentir prazer pela revelação e reconhecimento mais ou menos consciente de um impulso reprimido. Freud acrescenta ainda que, além disso, o espectador pode se identificar com o herói da peça, sem ter que pagar o preço de passar, em sua vida, pelo sofrimento e risco que tal papel encerra. Ele sabe que se trata aí apenas 
de um jogo teatral, que não ameaça sua segurança pessoal. Freud (1942/1980) assinala, entretanto, que, durante a encenação da peça, o espectador neurótico não experimenta apenas um sentimento de prazer, mas é também tomado por um sentimento interno de resistência, fruto de conflitos intrapsíquicos.

Um dos estudiosos que deu continuidade a essa perspectiva de Freud foi Mannoni (1969). Para ele, o espectador de teatro sente a presença do inconsciente sob a forma de uma estranha novidade que acompanha o retorno do recalcado. Ele aceita o que vê como parte de sua realidade e, tal como no sonho, efetua uma realização de desejo. Para esse autor, é justamente porque o teatro se coloca como ilusório que ele permite o trabalho com o recalcado. O espectador sabe que a peça é uma construção artística, que não vai invadir concretamente o seu cotidiano. Tal situação possibilita a liberação de impulsos recalcados durante a encenação. Mannoni (1969) avança, entretanto, na compreensão desse trabalho com o recalcado quando assinala que o teatro não apenas tem o efeito de liberação psíquica, mas também o de consolidação das defesas. Ele põe em movimento o processo de identificação do espectador reforçando, posteriormente, as projeções e os mecanismos de defesa. Para ele, o teatro não apenas convoca, mas reestrutura as identificações, possibilitando, assim, uma redução das ilusões.

As considerações de Mannoni (1969) nos permitem pensar os efeitos da encenação teatral sobre o Rei Cláudio na peça Hamlet. Aí, o teatro é colocado como um acontecimento que produz um corte, uma mudança. $\mathrm{O}$ teatro dentro do teatro, ou a outra cena da cena fez com que Cláudio ficasse profundamente abalado durante o espetáculo que lhe foi encenado e passasse a se censurar sobre o assassinato praticado contra seu irmão. Tal perspectiva aponta para um aspecto importante: não se sai o mesmo do teatro, como não se sai o mesmo de uma sessão de psicanálise. O teatro mobiliza, reestrutura a vida psíquica e, nesse sentido, podemos afirmar, junto a Badiou (1999), que ele é um acontecimento singular do pensamento. O teatro possibilita a produção de novas idéias, de novas associações, de modo que o público vai ao teatro para ser surpreendido. Esse sentimento de surpresa também é muito presente no processo analítico e aponta para o trabalho com o recalcado.

Um outro aspecto interessante dessa passagem em Hamlet é o seguinte: se na obra de Freud (1900/1980), o sonho dentro do sonho é colocado como um fragmento da realidade, também na peça Hamlet o teatro dentro do teatro aponta para esta dimensão. Mas se o teatro tem o poder de afetar o espectador pelos recursos de sua própria linguagem, isso não quer dizer que ele produza identificações que apontem, necessariamente, para o campo factual. A realidade psíquica é sempre o que está em jogo no processo de identificação entre o público e os personagens da peça (Freud, 1942/1980). Entretanto, Hamlet interpretou a reação de seu tio ao espetáculo de teatro como o signo de um fato, não de um desejo não realizado, o que nos mostra o quanto a fantasia engendra a realidade.

Que a verdade só pode ser apreendida indiretamente é um aspecto que também podemos verificar no diálogo entre Polônio e seu criado Reinaldo. Nele, Polônio pede a Reinaldo que visite o seu filho Laertes em Paris, que lhe dê dinheiro e carta, mas que antes, busque informações sobre o seu procedimento no que diz respeito a jogo, bebida, mulheres, brigas e duelos. Orienta-o no sentido de utilizar a mentira, a fim de apreender a verdade. Propõe a ele que, diante das pessoas, impute a seu filho faltas leves, para que estas sejam, então, confirmadas ou negadas por elas. Vejamos o que ele lhe diz:

A isca da mentira apanha a carpa da verdade; é desta forma que nós, pessoas experimentadas e prudentes, com artimanhas e atacando as coisas de lado, encontramos indiretamente a verdade direta; e é com isto que vos ensinei e com os conselhos que vos dou, que haveis de descobrir como se porta meu filho (Shakespeare, 1601/2003, p. 118).

\section{O Desejo}

Essas poucas considerações extraídas do Hamlet nos permitem visualizar o quanto a busca da verdade é algo presente nessa peça de Shakespeare. Se o desejo de saber move os seus personagens, também é algo que se encontra no cerne da clínica psicanalítica. Nela, o analisando é desde o início movido pelo desejo de saber a verdade sobre o seu próprio desejo. É nesse sentido que a verdade é, por excelência, o objeto da pulsão epistemofílica. As relações entre a verdade e o saber, na clínica psicanalítica, foram problematizadas por Lacan em alguns de seus seminários, dentre eles o Seminário 17, no qual apresentou, pela primeira vez, os quatro discursos pelos quais se dá o laço social: o discurso universitário, o discurso do mestre, o discurso da histérica e o discurso do analista. Ao se referir ao discurso da histérica, Lacan (1992) ressaltou que tal discurso se caracteriza pela busca de um mestre, detentor de saber. Nessa perspectiva, enquanto o desejo de saber visa à verdade, como vimos há pouco, o discurso da histérica visa ao saber, localizado no campo do outro. Ou seja, não é o desejo de saber que conduz ao saber, mas o discurso da histérica.

No processo de análise, num primeiro momento, o analisando crê que o outro sabe e detém a verdade sobre o seu desejo. Crê, ainda, que, posteriormente, o analista irá lhe falar sobre essa verdade. A verdade está aí colocada, portanto, como um saber localizado no outro. É o outro quem sabe. Tal não é a situação, num segundo momento, quando o analisando passa a considerar que é ele quem sabe a verdade sobre o seu desejo e que irá descobri-la. O analista, nesse momento, passa a ser aquele que irá ajudá-lo a encontrar a verdade, que o analisando sabe inconscientemente. Se nesses dois primeiros momentos a verdade tem o estatuto de um saber que pode ser apreendido, num terceiro momento esta situação se inverte. Agora, é o saber que passa a ter o estatuto de verdade. $\mathrm{O}$ analisando, então, considera que não pode descobrir toda a verdade porque ela é inatingível. Nem ele nem o analista podem fazê-lo porque não há como saber toda a verdade. A partir desse momento surge, em análise, um novo analista. Do lado do analista, portanto, o saber se situa no lugar da verdade, como assinala Lacan (1992) no discurso do analista. Trata-se, aí, de um saber incompleto, com furo. Um saber como verdade é, portanto, a estrutura mesma da interpretação, na medida em que não é possível 
uma interpretação última e cabal dos fenômenos psíquicos. A verdade é sempre múltipla, parcial e a interpretação reflete esta parcialidade.

No caso específico de Hamlet, conhecemos a leitura que Lacan (1958) fez a partir da vacilação desse personagem diante de seu próprio desejo. Com sua mãe Gertrudes, Hamlet suspende as palavras de interdição dirigidas contra o seu relacionamento com o Rei Cláudio. Na presença de Ofélia, recusa o amor que sentia por ela para só recobrá-lo em seu túmulo de morte, quando então sente ciúme do luto de Laertes. Diante do Rei Cláudio, adia o ato de seu assassinato para só consumá-lo quando confrontado com sua própria morte. O recobro do seu desejo só se dá, portanto, nos momentos em que ele é confrontado com a perda, a morte, a castração. Hamlet sempre adia a hora da verdade, de seu encontro com o próprio desejo (Lacan, 1958, 1966). Diferentemente de Waldock (1931), para quem uma peça não é uma mina de motivos secretos, Lacan (1958) considerou o Hamlet como o drama de uma subjetividade que nos mostra a estrutura mesma do desejo. Um dos pontos centrais dessa tragédia do desejo, em torno do qual gira a verdade, é a morte, a morte do pai. Sabemos que essa obra foi escrita logo após o falecimento do pai de Shakespeare (Freud, 1900/1980). A verdade sobre a morte do pai é, pois, um dos grandes enigmas que move toda a humanidade, constituindo-se a chave mesma daquilo com que lida a psicanálise (Lacan, 1992). Ao longo da peça, Hamlet chegou à suposta verdade histórica sobre a morte de seu pai. Explicá-la apenas através do Édipo é lançar mão de um recurso que tem a função de tamponar o que é da ordem do Real, do inominável. Quando Lacan (1992) propôs que se fosse além do Édipo, estava apontando, justamente, dentre outras coisas, para essa dimensão do impossível de saber.

\section{Considerações Finais}

Através do presente estudo pudemos explorar, tanto na peça Hamlet quanto na direção do processo de análise, a relação do sujeito com a verdade. Vários aspectos ligados ao problema da verdade, tais como a sua estrutura de ficção, relação com o desejo, as pulsões e a moralidade foram aqui trabalhados. Apesar de se tratarem de dois campos distintos, uma comparação foi estabelecida entre a clínica psicanalítica e o teatro, mostrando como neles a busca e a revelação gradual da verdade produzem modificações na subjetividade. Além disso, a impossibilidade de uma apreensão última de toda a verdade, assim como a problematização de suas relações com o saber, mostraram ser um fio condutor importante para pensar os diversos momentos do processo de análise.

Nessa direção, verificamos que, na clínica, trata-se de fazer com que o paciente se defronte com a castração na busca de sua verdade. Que as palavras possam conduzir ao puro silêncio, ao que é da ordem do inefável, é o que pode ocorrer ao final de uma psicanálise. Nesse momento, o analisando se depara com a dimensão Real da verdade, no que ela tem, em última instância, de mudez e intangibilidade. Ele percebe que toda verdade é, sempre, uma meia-verdade (Lacan, 1992). Retomando Freud (1937/1980), para quem não há análise sem amor à verdade, Lacan (1992) sublinha que aí deve ser situado o amor à castração, de modo que a verdade está ligada à impotência e ao que é da ordem do impossível. O que se espera, então, de um analista, é que ele faça funcionar seu saber em termos de verdade, como vimos, e não a verdade em termos de saber. $\mathrm{O}$ analista conduz o processo de análise fazendo com que tudo seja re-questionado. Ele não reduz a fala do analisando ao saber instituído pela teoria. Com isso se produz uma queda de saber e se revela a natureza própria da verdade, que é a de sempre se ocultar.

Podemos considerar que a linguagem poética de Hamlet aponta para essa dimensão da verdade, em sua capacidade de nos relançar para um outro lugar que não aquele da intencionalidade consciente da fala. A palavra, em Hamlet, possibilita o encontro com a falta através dos impasses e enigmas que ela mesma produz. O movimento de busca da verdade é, portanto, a via régia da castração. Um dos maiores poetas de todos os tempos, Fernando pessoa, também nos revelou isso, através dos breves versos com os quais finalizo este texto agora:

\begin{abstract}
"Quem vende a verdade, e a que esquina?
Quem dá a hortelã com que temperá-la?

Quem traz para casa a menina

E arruma as jarras da sala?
\end{abstract}

Quem interroga os baluartes

E conhece o nome dos navios?

Dividi o meu estudo inteiro em partes

E os títulos dos capítulos são vazios..."

(Pessoa, 1969, p. 521)

\section{Referências}

Badiou, A. (1999). Conferências de Alan Badiou no Brasil. Belo Horizonte: Autêntica.

Bloom, H. (2000). Shakespeare: a invenção do humano. Rio de Janeiro: Objetiva.

Bloom, H. (2004). Hamlet - Poema Ilimitado. Rio de Janeiro: Objetiva.

Cantor, P. A. (2004). Shakespeare - Hamlet. Cambridge: University Press.

Freud, S. (1980). Carta 71. Em Edição Standard das Obras Psicológicas Completas Vol.1 (J. Salomão, Trad.). Rio de Janeiro: Imago. (Trabalho original publicado em 1969)

Freud, S. (1980). A interpretação dos sonhos. Em Edição Standard das Obras Psicológicas Completas Vols. 4 e 5 (J. Salomão, Trad.). Rio de Janeiro: Imago. (Trabalho original publicado em 1900)

Freud, S. (1980). Análise terminável e interminável. Em Edição Standard das Obras Psicológicas Completas Vol. 23 (J. Salomão, Trad.). Rio de Janeiro: Imago. (Trabalho original publicado em 1937)

Freud, S. (1980). Personagens psicopáticos no palco. Em Edição Standard das Obras Psicológicas Completas Vol. 7 (J. Salomão, Trad.). Rio de Janeiro: Imago. (Trabalho original publicado em 1942)

Iasi, M. L. (2002). O dilema de Hamlet. São Paulo: Boitempo.

Jones, E. (1949). Hamlet and Oedipus. New York: Doubleday Anchor. 
Lacan, J. (1998). Para-além do "Princípio de realidade". Em Escritos (pp. 77-95). Rio de Janeiro: Jorge Zahar. (Trabalho original publicado em 1936)

Lacan, J. (1998). Formulações sobre a causalidade psíquica. Em Escritos (pp. 152-194). Rio de Janeiro: Jorge Zahar. (Trabalho original publicado em 1950)

Lacan, J. (1998). Seminário a carta roubada. Em Escritos (pp. 1366). Rio de Janeiro: Jorge Zahar. (Trabalho original publicado em 1957)

Lacan, J. (1998). Juventude de Gide ou a Letra e o Desejo. Em Escritos (pp. 749-775). Rio de Janeiro: Jorge Zahar. (Trabalho original publicado em 1958)

Lacan, J. (1958). O seminário 6: o desejo e sua interpretação (1958-59). Associação Psicanalítica de Porto Alegre, Porto Alegre: s/d.

Lacan, J. (1998). Subversão do sujeito e dialética do desejo no inconsciente freudiano. Em Escritos (pp. 807-842). Rio de Janeiro: Jorge Zahar. (Trabalho original publicado em 1960)

Lacan, J. (1985). O seminário livro 11: os quatro conceitos fundamentais da psicanálise. Rio de Janeiro: Jorge Zahar. (Trabalho original publicado em 1964)

Lacan, J. (1998). A ciência e a verdade. Em Escritos (pp. 869-892). Rio de Janeiro: Jorge Zahar. (Trabalho original publicado em 1966)

Lacan, J. (1966). O seminário 14: a lógica do fantasma. (19661967) Versão argentina em CD Rom Los Seminarios Jacques Lacan, s/d.

Lacan, J. (1992). O seminário livro 17: o avesso da psicanálise (1969-70). Rio de Janeiro: Jorge Zahar.

Lins, M. I. A. (2002). O mistério de Hamlet. Natureza Humana, 4(1), 33-57.
Mannoni, O. (1969). Clefs pour l'immaginaire ou l' autre scène. Paris: Seuil.

Motta, V. D. S. (2006). Nelson Rodrigues e uma poética do fragmento: o inconsciente em cena. Tese de doutorado, Universidade Federal da Bahia, Salvador.

Pereira, M. E. C. (2002). "Boa noite, amado príncipe". Ou notas psicanalíticas sobre a insônia, o repouso e a morte na tragédia de Hamlet. Psyché, VI(10), 19-38.

Pessoa, F. (1969). Obra poética. Rio de Janeiro: Companhia José Aguilar.

Pimstein, F. (1972). Hamlet - anatomia de la ambigüedad. Santiago: Editorial Universitária.

Quijano, M. (1962). Hamlet y sus críticos. México: Universidad Nacional Autónoma de México.

Shakespeare, W. (2003). Hamlet. São Paulo: Planeta DeAgostini. (Trabalho original publicado em 1601)

Vygotsky, L. S. (1999). A tragédia de Hamlet, o príncipe da Dinamarca. São Paulo: Martins Fontes.

Waldock, M. A. A. J. A. (1931). Hamlet-a study in critical method. Cambridge: University Press.

Williamson, C. (1950). Readings on the character of Hamlet. London: George Allen \& Unwin.

Recebido em 23.02.2006

Primeira decisão editorial em 27.03.2006

Versão final em 23.06.2006

Aceito em 29.03.2007 